\title{
Left vocal cord paralysis and dysphagia in mitral valve disease
}

\author{
A A MORGAN, A J MOURANT \\ From University College Hospital, London; and the Cardiac Department, The London Hospital, \\ London
}

SUMMARY Two cases of severe mitral stenosis with both hoarseness, caused by left vocal cord palsy, and dysphagia are described. This combination in the same patient has not, to our knowledge, been previously described.

Previous studies have firmly established that vocal cord paralysis in mitral stenosis is a result of compression of the left recurrent laryngeal nerve as it passes around the aortic arch. It is suggested that dysphagia may also develop as a result of neurological damage, in this case to autonomic nerve plexuses supplying the oesophagus, leading to abnormal peristalsis and enabling external compression by a tense left atrium sufficient to cause symptoms.

Left vocal cord paralysis and dysphagia are uncommon complications of mitral valve disease. Since first described by Ortner, ${ }^{1}$ studies have indicated that left recurrent nerve palsy occurs in less than 1 per cent of patients with mitral stenosis. ${ }^{2}$ Dysphagia has been reported in only a small number of patients. ${ }^{3-6}$

After an extensive search of the world's publications we have been unable to find any reported cases of mitral stenosis with both hoarseness, Received for publication 27 July 1979 caused by left recurrent laryngeal nerve palsy, and dysphagia. We report two such patients and discuss the mechanisms by which the abnormalities may arise.

\section{Case 1}

This patient developed palpitation at the age of 55, when she was found to have mitral stenosis with atrial fibrillation; there was no history of rheumatic fever. The palpitation settled with digoxin, and she

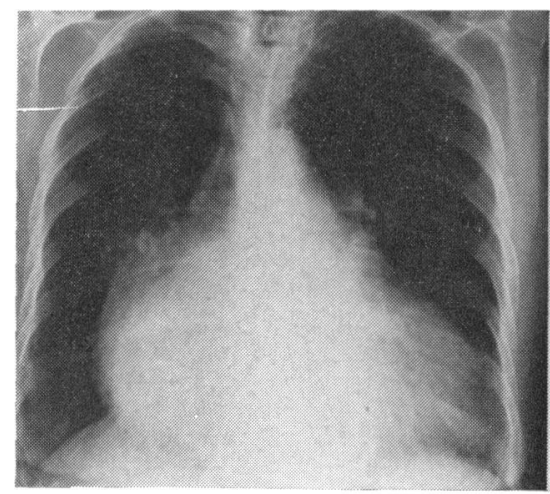

a

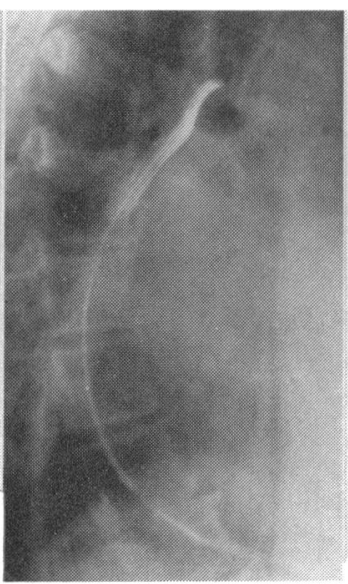

b

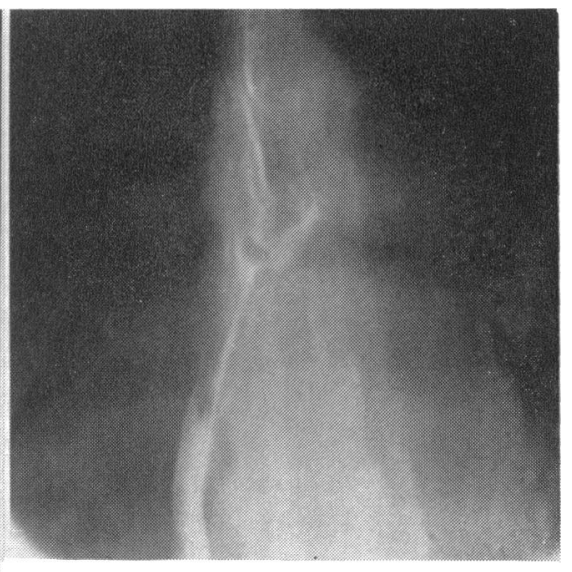

C

Fig. 1 Radiological investigations in case 1. (a) Chest $\mathrm{x}$-ray, showing conspicuous cardiomegaly with gross left atrial enlargement. (b) Barium swallow (right anterior oblique projection) showing backward displacement of the oesophagus around the enlarged left atrium. (c) Hilar tomography during the barium swallow showing delayed passage of contrast material at the angle of tracheal bifurcation and pronounced upward displacement of the left main bronchus. 
remained well for 10 years when mild effort dyspnoea developed. Five years later she became hoarse, and subsequent laryngoscopy revealed complete paralysis of the left vocal cord. Over the next two years she noticed difficulty in swallowing solid foods, which felt to her as if they were sticking in the middle of her chest. She had also become more breathless with effort and slept with four pillows to avoid orthopnoea.

On examination, she was in atrial fibrillation with a slight increase in jugular venous pressure, right ventricular enlargement, and the auscultatory findings of severe mitral stenosis. The electrocardiogram was compatible with these findings. Her chest $x$-ray film showed distinct cardiomegaly (Fig. 1a). At cardiac catheterisation the indirect left atrial pressure was $30 \mathrm{mmHg}$ (mean) and she was found to have an end-diastolic gradient across the mitral valve of $15 \mathrm{mmHg}$ and a pulmonary artery pressure of $90 / 40 \mathrm{mmHg}$. Left ventricular angiography showed trivial mitral reflux. Finally, barium studies showed considerable backward displacement of the oesophagus with delayed passage of dye through the mid-portion (Fig. 1b), and hilar tomography during the barium examination indicated gross widening of the angle of tracheal bifurcation (Fig. 1c).

A diagnosis of severe mitral stenosis with pulmonary hypertension was made. She declined operation and is being treated with digoxin and diuretics.

\section{Case 2}

At the age of 41 this housewife underwent mitral valvotomy because of increasing breathlessness secondary to mitral stenosis. There was no history of rheumatic fever. Ten years later she sustained a left hemiplegia from which she made a complete recovery. She was virtually asymptomatic for a further three years, when effort dyspnoea and ankle oedema developed, and two years later she was admitted to hospital in acute pulmonary oedema which improved with diuretic treatment. She underwent cardiac catheterisation when severe mitral stenosis with a gradient of $15 \mathrm{mmHg}$ was found. Pulmonary artery pressure was $55 / 20 \mathrm{mmHg}$, with mean indirect left atrial pressure of $20 \mathrm{mmHg}$ (' $v$ ' wave, $30 \mathrm{mmHg}$ ). Angiography disclosed trivial
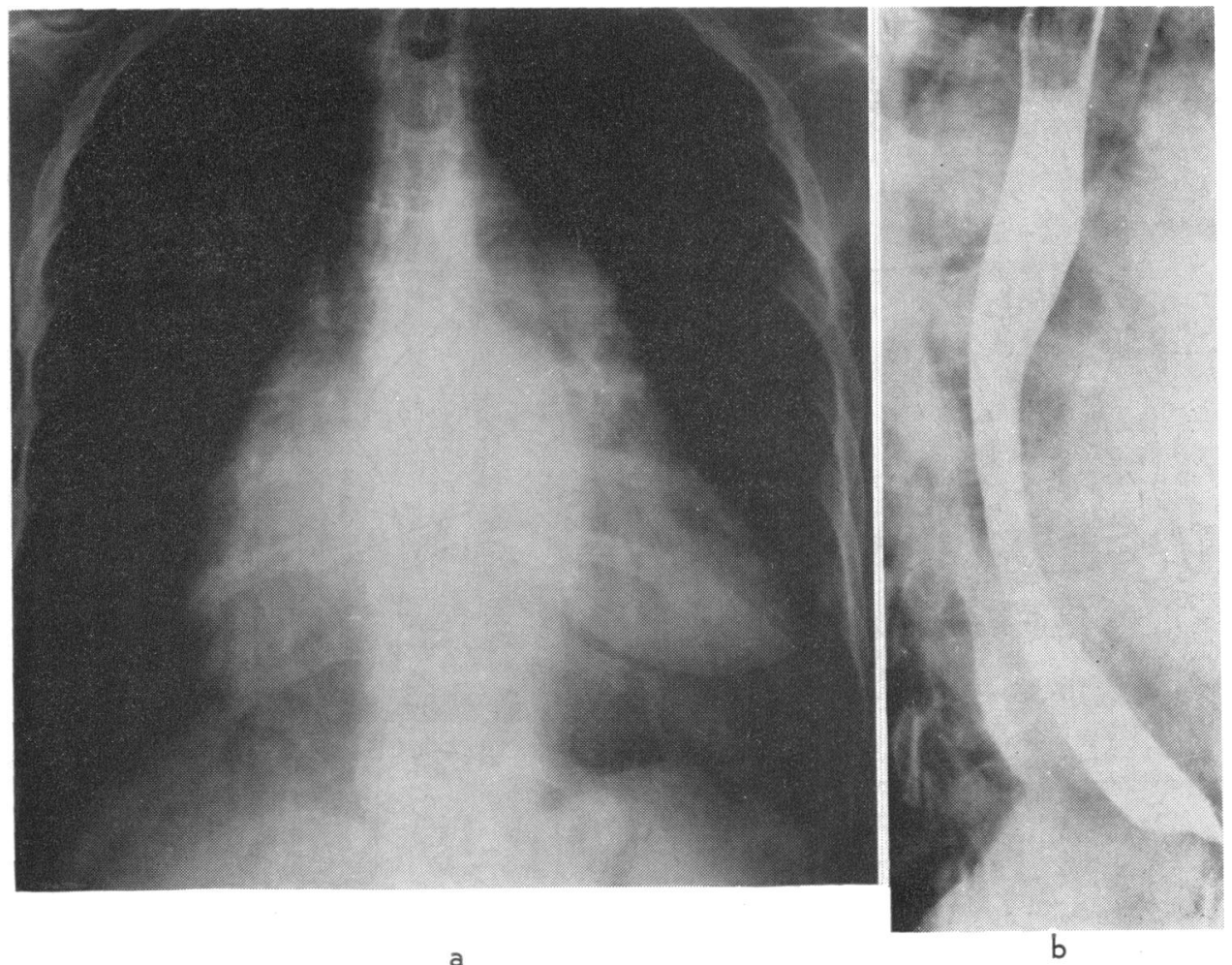

Fig. 2 Radiological investigations in case 2. (a) Penetrated PA chest $x$-ray film showing cardiomegaly, left atrial enlargement, prominent left pulmonary artery, and upward displacement of the left main bronchus. (b) Barium swallow (right anterior oblique projection) showing compression and backward displacement of the oesophagus. 
mitral regurgitation and slight aortic regurgitation; left ventricular contraction was normal. She declined operation but subsequently became increasingly breathless with effort and developed both dysphagia and hoarseness. At laryngoscopy the left vocal cord was noted to be completely paralysed.

She was readmitted to hospital. The venous pressure was slightly raised and both ventricles were clinically enlarged. Auscultatory findings were of severe mitral stenosis and slight aortic regurgitation. The electrocardiogram showed right axis deviation with digoxin effect and her chest $x$-ray film showed severe cardiomegaly with left atrial enlargement and upward displacement of the left main bronchus (Fig. 2a). At barium swallow oesophageal displacement and compression were shown (Fig. 2b).

She underwent mitral valve replacement surgery with a Björk-Shiley prosthesis and her postoperative progress was uneventful, though she was still hoarse when examined six weeks later. She died suddenly two months after operation but there was no necropsy.

\section{Discussion}

Left vocal cord paralysis in mitral stenosis is caused by compression of the left recurrent laryngeal nerve between the aortic arch and the pulmonary artery? which is displaced upwards by the enlarged left atrium (Fig. 3a). Enlarged tracheobronchial lymph nodes may be an additional contributory factor. ${ }^{8}$ The mechanisms of dysphagia in association with mitral valve disease are less certain. Normal swallowing is controlled and co-ordinated by autonomic nerve plexuses in the oesophagus. These plexuses derive their nerve supply from the vagus nerves and thoracic sympathetic outflow; fibres form the posterior pulmonary plexuses from which four or five cords pass posteriorly to the middle of the oesophagus. The cords then divide into the oesophageal plexus which supplies afferent and efferent fibres (Fig. 3b). During normal peristaltic contraction, pressure within the oesophageal lumen reaches peak values of 40 to $80 \mathrm{mmHg}{ }^{9}$

In severe mitral stenosis the enlarged left atrium displaces the oesophagus, usually backwards and to the right. ${ }^{56}$ Pressure within the left atrium is increased and may interfere with normal oesophageal peristalsis sufficient to cause dysphagia, though the maximum pressure applied to the oesophagus by the left atrium is never likely to exceed peak intra-oesophageal pressure during active peristalsis. However, autonomic nerve fibres stretched between the posterior pulmonary plexuses and the oesophagus may themselves be damaged, resulting in abnormal oesophageal peristalsis and
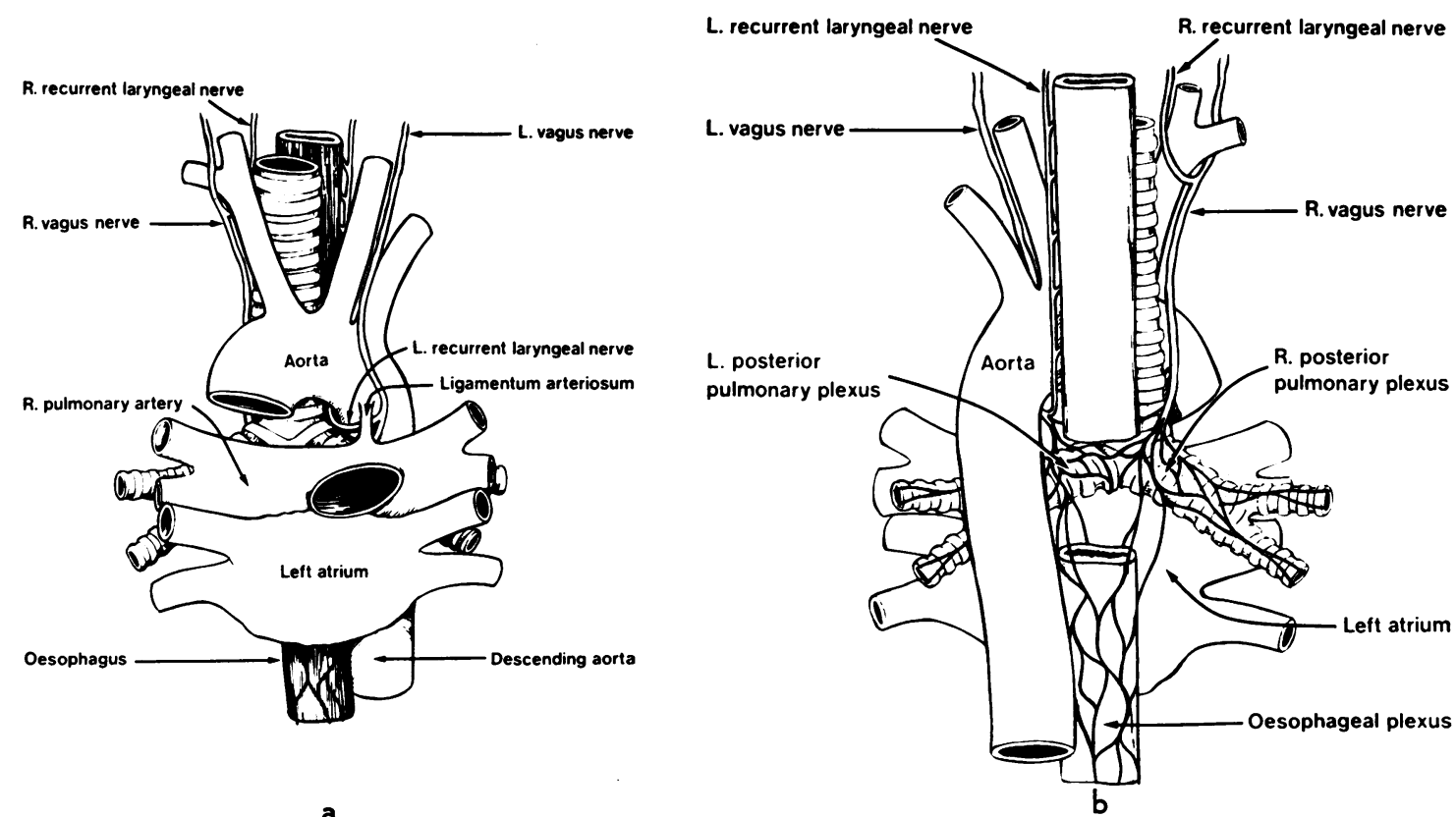

a

Fig. 3 Normal anatomical relations of the left atrium (drawn by $\mathcal{F}$ Abbott). (a) Anterior view showing the left recurrent laryngeal nerve passing around the aortic arch, behind the ligamentum arteriosum and above the left pulmonary artery and left main bronchus. (b) Posterior view showing division of the vagus nerves into posterior pulmonary plexi, from which fibres pass over the left atrium to the oesophagus. 
an increased likelihood to dysphagia developing as a result of external compression from the enlarged and tense left atrium.

The two patients described in this paper developed both hoarseness and dysphagia as the severity of the mitral valve disease increased. In each case hoarseness was found at laryngoscopy to be caused by left vocal cord paralysis. Dysphagia was not sufficient to cause extreme difficulty in swallowing in either patient though both described the sensation of food sticking at mid-thorax level. Barium swallow showed conspicuous oesophageal displacement around an enlarged left atrium in each patient, and there is no doubt that the degree of displacement would have been sufficient to stretch, and possibly damage, nerves supplying the oesophageal plexus.

We thank Dr W Brigden for permission to report these cases under his care and for his help in the preparation of this paper.

\section{References}

${ }^{1}$ Ortner N. Recurrenslähmung bei Mitralstenose. Wien Klin Wochenschr 1897; 10: 753-62.

${ }^{2}$ Wood PH. Diseases of the heart and circulation, 3rd ed.

London: Eyre \& Spottiswoode, 1968: 624.

${ }^{3}$ Bloomfield AL. Dysphagia with disorders of the heart and great vessels. Am F Med Sci 1940; 200: 289-99.

${ }^{4}$ Dines DE, Anderson MW. Giant left atrium as a cause of dysphagia. Ann Intern Med 1966; 65: 758-61.

5le Roux BT, Williams MA. Dysphagia megalatriensis. Thorax 1969; 24: 603-6.

'Whitney B, Croxon R. Dysphagia caused by cardiac enlargement. Clin Radiol 1972; 23 : 147-52.

${ }^{2}$ White PD. Heart disease, 3rd ed. New York: Macmillan, 1947: 615.

${ }^{8}$ Dolowitz DA, Lewis CS. Left vocal cord paralysis associated with cardiac disease. Am $\mathcal{F}$ Med 1948; 4: 856-62.

'Earlam R. Clinical tests of oesophageal function. London: Crosby Lockwood Staples, 1976: 42.

Requests for reprints to Dr A J Mourant, Cardiac Department, The London Hospital, Whitechapel, London E1 1BB. 